\title{
Liposome-delivered baicalein induction of myeloid leukemia K562 cell death via reactive oxygen species generation
}

\author{
SCARLET XIAOYAN WANG, XUESONG WEN, CELIA BELL and SANDRA APPIAH \\ Department of Natural Sciences, Faculty of Science and Technology, Middlesex University, London NW4 4BT, UK
}

Received September 11, 2017; Accepted December 18, 2017

DOI: $10.3892 / \mathrm{mmr} .2018 .8396$

\begin{abstract}
Baicalein (BL), a potential cancer chemopreventative flavone, has been reported to inhibit cancer cell growth by inducing apoptosis and causing cell cycle arrest in various human cancer cell models. Delivery of BL via nanoliposomes has been shown to improve its oral bioavailability and long-circulating property in vivo. However, the role of $\mathrm{BL}$ in the inhibition of human chronic myeloid leukemia (CML) K562 cell growth and its underlying mechanisms has yet to be elucidated. In the present study, BL was formulated into liposomes with different sizes to improve its solubility and stability. The cytotoxic and pro-apoptotic effects of free BL and liposomal BL were also evaluated. The results demonstrated that $100 \mathrm{~nm}$ liposomes were the most stable formulation when compared with 200 and $400 \mathrm{~nm}$ liposomes. Liposomal BL inhibited K562 cell growth as efficiently as free $\mathrm{BL}$ (prepared in DMSO), indicating that the liposome may be a potential vehicle to deliver BL for the treatment of CML. Flow cytometry analysis showed that there was significant $(\mathrm{P}<0.005)$ cell cycle arrest in the sub-G1 phase (compared with vehicle control), indicating cell apoptosis following $20 \mu \mathrm{M}$ liposomal BL or free BL treatment of K562 cells for $48 \mathrm{~h}$. The induction of cell apoptosis by all BL preparations was further confirmed through the staining of treated cells with Annexin V-fluorescein isothiocyanate/propidium iodide. A significant increase in reactive oxygen species (ROS) generation was observed in free BL and liposomal BL treated cells, with a higher level of ROS produced from those treated with free BL. This indicated that cell apoptosis induced by BL may be via ROS generation and liposome delivery may further extend the effect through its long-circulating property.
\end{abstract}

Correspondence to: Dr Scarlet Xiaoyan Wang or Dr Sandra Appiah, Department of Natural Sciences, Faculty of Science and Technology, Middlesex University, The Burroughs, Hendon, London NW4 4BT, UK

E-mail: x.wang@mdx.ac.uk

E-mail: s.appiah@mdx.ac.uk

Key words: baicalein, liposomes, chronic myeloid leukemia, cell cycle, apoptosis, reactive oxygen species

\section{Introduction}

Chronic myeloid leukemia (CML) is a myeloproliferative disorder that is characterized by the unregulated growth of myeloid leukemia cells in the bone marrow and their accumulation in the blood (1). Epidemiologic data suggest that CML incidence is one to two per 100,000 individuals, with $15-20 \%$ of adult leukemia cases being CML (2). While CML is commonly treated with tyrosine kinase inhibitors, an increase in drug resistance has been reported along with adverse side effects (3).

Baicalein (BL) is a bioactive flavone derived from the root of traditional Chinese medicine herb Scutellaria baicalensis Georgi, with broad antitumor activity against ovarian (4), prostate (5), breast (6), cervical (7) and lung (8) cancers. However, clinical application of free BL has been limited by its extensive first-pass metabolism, low aqueous solubility, poor bioavailability, short half-life $\left(\mathrm{t}_{1 / 2}, 10 \mathrm{~min}\right)$ and its easy oxidation (9-16). About $76 \%$ of the dose was found to be circulating as its conjugated metabolites even after intravenous administration of BL in rats (10). Tian et al (17) demonstrated that the absolute bioavailability of BL ranges from 13.1 to $23.0 \%$ when it was administered via oral and intravenous routes in monkeys. Nanostructured lipid carriers such as liposomes have been developed to improve the stability and bioavailability of BL (11).

Liposomes have been used recently as popular nanovesicles for administration of oral drugs because they have good biocompatibility and biodegradability due to their similarity in structure to the cell-surface phospholipid bilayer. They have also been shown to display excellent drug loading rates, as well as targeting and slow releasing actions, enhanced oral bioavailability and long-circulating properties (18-25). Despite these advantages, there are no studies in the literature describing the use of liposomes to deliver BL to K562 cells or to investigate the antitumor activities of free $\mathrm{BL}$ and liposomal BL on these cells.

Previous investigations have shown that $\mathrm{BL}$ has multiple biological activities, including anti-inflammatory (26) anti-microbial (27) and antioxidant (28) properties. BL exerts an antitumor effect by promoting the apoptosis or inhibiting the proliferation of cancer cells (29-32) through multiple signalling pathways including the cell proliferation pathway, the cell apoptosis and caspase activation pathway, the tumor suppressor pathway and the protein kinase pathway $(33,34)$. However, the exact mechanism of 
apoptosis and its related pathways induced by BL is not yet fully understood.

In the present study, we evaluated different sizes of liposome formulations for the delivery of BL. We further investigated the cytotoxicity and pro-apoptotic effects of BL and liposomal BL on CML K562 cells. The mechanism involved in this process was also explored.

\section{Materials and methods}

Materials. Soy phosphatidylcholine (PC) was purchased from Avanti Polar Lipids, Inc. (Alabaster, AL, USA). Meth oxypolyethyleneglycol-di-stearoyl-phosphatidylethanolamine (DSPE-PEG2000, with mPEG MW2000 Da) was obtained from Genzyme (Oxford, UK). Cholesterol (Chol), PBS, dialysis tubing, propidium iodide (PI), RNase and BL were all purchased from Sigma-Aldrich (UK). Methanol, dichloromethane, CyQUANT ${ }^{\circledR}$ Cell Proliferation Assay kit and Annexin V-FITC/PI Apoptosis Detection kit were both from Thermo Fisher Scientific (Loughborough, UK). RPMI-1640, L-glutamine, penicillin-streptomycin and fetal bovine serum (FBS) were all from Invitrogen Life Technologies (UK). The CellTiter $96{ }^{\circledR} \mathrm{AQ}_{\text {ueous }}$ One Solution Cell Proliferation Assay (MTS) kit was purchased from Promega (Southampton, UK).

Liposome preparation and characterization. Three types of liposomes with different diameters were prepared. Liposomes were composed of soy PC, cholesterol, and methoxypolyethyleneglycol-di-stearoyl-phosphatidylethanolamine (DSPEPEG2000; Genzyme). Liposomes were prepared as described elsewhere (35). Briefly, the lipids were dissolved in methanol:dichloromethane 1:2 (v/v) at a PC:Cholesterol:DSPE-PEG2000 molar ratio of 78.9:19.7:1.4 at room temperature. BL was dissolved in the solvent with lipid mixture when formulating the liposomes. Different lipid/BL mass ratios were tested before settling on a fixed ratio of 10:1. The lipid mixtures were deposited on the side wall of the rotary glass vial by removing the solvent with nitrogen. The dried lipid films were hydrated in $10 \mathrm{mM}$ sodium phosphate buffer $\mathrm{pH}$ 7.4. This process led to the spontaneous formation of pegylated liposomes. The liposomes were then down-sized by passing through $0.1,0.2$ or $0.4 \mu \mathrm{m}$ polycarbonate membrane syringe filters (Whatman ${ }^{\circledR}$; Whatman, Inc., Clifton, NJ, USA) to produce lipo1, 2 and 3 suspensions, respectively. Free BL was removed by dialysis (14,000 Da cutoff membrane) against $10 \mathrm{mM}$ sodium phosphate buffer $\mathrm{pH} 7.4$ overnight. The size and $\zeta$-potential of liposomes were measured by dynamic light scattering on a Zetasizer-Nano ZS (Malvern Instruments Ltd., Malvern, UK).

Cell culture. Human leukemia K562 cells were purchased from ATCC (UK). Cells were cultured in RPMI-1640 media containing $10 \%$ fetal calf serum, $100 \mathrm{U} / \mathrm{ml}$ of penicillin, $100 \mathrm{mg} / \mathrm{ml}$ streptomycin in $75 \mathrm{~cm}^{2}$ flasks. The cells were grown in a humidified incubator containing $5 \% \mathrm{CO}_{2}$ and $95 \%$ air at $37^{\circ} \mathrm{C}$. Cells growing in the log phase and free from mycoplasma was used in this study.

Cytotoxicity assay. K562 cells were cultured at a density of $6 \times 10^{4}$ cells/well in 96-well plates overnight and treated with different concentrations of BL and control liposomes for 48 h. 3-(4,5-dimethylthiazol-2-yl)-5-(3-carboxymethoxyphe nyl)-2-(4-sulfophenyl)-2H-tetrazolium (MTS) solution (50 $\mu \mathrm{l})$ from CellTiter $96{ }^{\circledR} \mathrm{AQ}_{\text {ueous }}$ One Solution Cell Proliferation Assay kit was added to detect live cells in each well as per manufacturer's instructions. Cells were incubated for $30 \mathrm{~min}$ at $37^{\circ} \mathrm{C}$ with $95 \%$ air and $5 \% \mathrm{CO}_{2}$. The absorbance of the solution was measured at $490 \mathrm{~nm}$ by FLUOstar Omega (BMG Labtech, Aylesbury, UK). Each treatment was conducted in triplicates. The cell viability was expressed as a percentage of cell viability of liposome treated cells relative to untreated controls.

Cell proliferation assay. Cell proliferation assays were conducted with the CyQUANT ${ }^{\circledR}$ Direct Cell Proliferation Assay Kit (Thermo Fisher Scientific) to avoid interference from the color of BL. K562 cells were cultured at a density of 5,000 cells/well in 96-well plates overnight and treated with different concentrations of free $\mathrm{BL}$ or liposomal $\mathrm{BL}$ $(0.185-100 \mu \mathrm{M})$ for $48 \mathrm{~h}$. CyQUANT ${ }^{\circledR}$ Detection reagent $(100 \mu \mathrm{l})$ was added to detect live cells in each well as per manufacturer's instructions. Cells were incubated for $60 \mathrm{~min}$ at $37^{\circ} \mathrm{C}$ with $95 \%$ air and $5 \% \mathrm{CO}_{2}$. The fluorescence of the solution was recorded at 485 (ex)/520 (em) nm by FLUOstar Omega (BMG Labtech). Cell viability was expressed as a percentage of cell survival of treated cells relative to untreated controls.

Cell cycle and cell apoptosis analysis. Approximately $1 \times 10^{5} \mathrm{~K} 562$ cells/well in 96-well plates were incubated with $20 \mu \mathrm{M}$ free $\mathrm{BL}$ or liposomal $\mathrm{BL}$ for $48 \mathrm{~h}$. The cells were centrifuged, resuspended in binding buffer and treated with Annexin V-FITC and PI for $5 \mathrm{~min}$ before analysis for cell apoptosis. For cell cycle analysis, the cells were harvested, washed and fixed gently (drop by drop) in $70 \%$ ethanol and kept at $4{ }^{\circ} \mathrm{C}$ for $30 \mathrm{~min}$. The cells were then resuspended in PBS containing $40 \mu \mathrm{g} / \mathrm{ml} \mathrm{PI}$ and $0.1 \mathrm{mg} / \mathrm{ml}$ RNase for cell cycle analysis. After $30 \mathrm{~min}$ incubation at $37^{\circ} \mathrm{C}$ in the dark, 10,000 cells/sample were analyzed were analysed for DNA content by flow cytometry on BD FACSCalibur (BD Biosciences, Oxford, UK) and the cell cycle distribution was determined using a CellQuest software (Becton-Dickinson, Franklin Lakes, NJ, USA). The percentage of cell population that had undergone apoptosis and those in different phases of the cell cycle were assessed accordingly.

Intracellular reactive oxygen species (ROS) assay. The measurement of intracellular ROS was determined by the Cellular Reactive Oxygen Species Detection Assay kit (Abcam, Cambridge, UK), which uses the cell permeant reagent 2',7'-dichlorofluorescin diacetate (DCFDA), a fluorogenic dye that measures ROS activity within the cell. Briefly, K562 cells were cultured in complete phenol-red free RPMI medium at a density of $1.5 \times 10^{5}$ cells/well in 96-well plates and were treated with $20 \mu \mathrm{M}$ BL or liposomal BL for $48 \mathrm{~h}$. After the incubation time, the cell treatments were overlaid with $20 \mu \mathrm{M}$ DCFDA $(100 \mu \mathrm{l})$ and incubated at $37^{\circ} \mathrm{C}$ for further $30 \mathrm{~min}$ in the dark. The fluorescence of the treatments was detected at the excitation and emission spectra of 485 and $520 \mathrm{~nm}$, respectively, by FLUOstar Omega (BMG Labtech). 

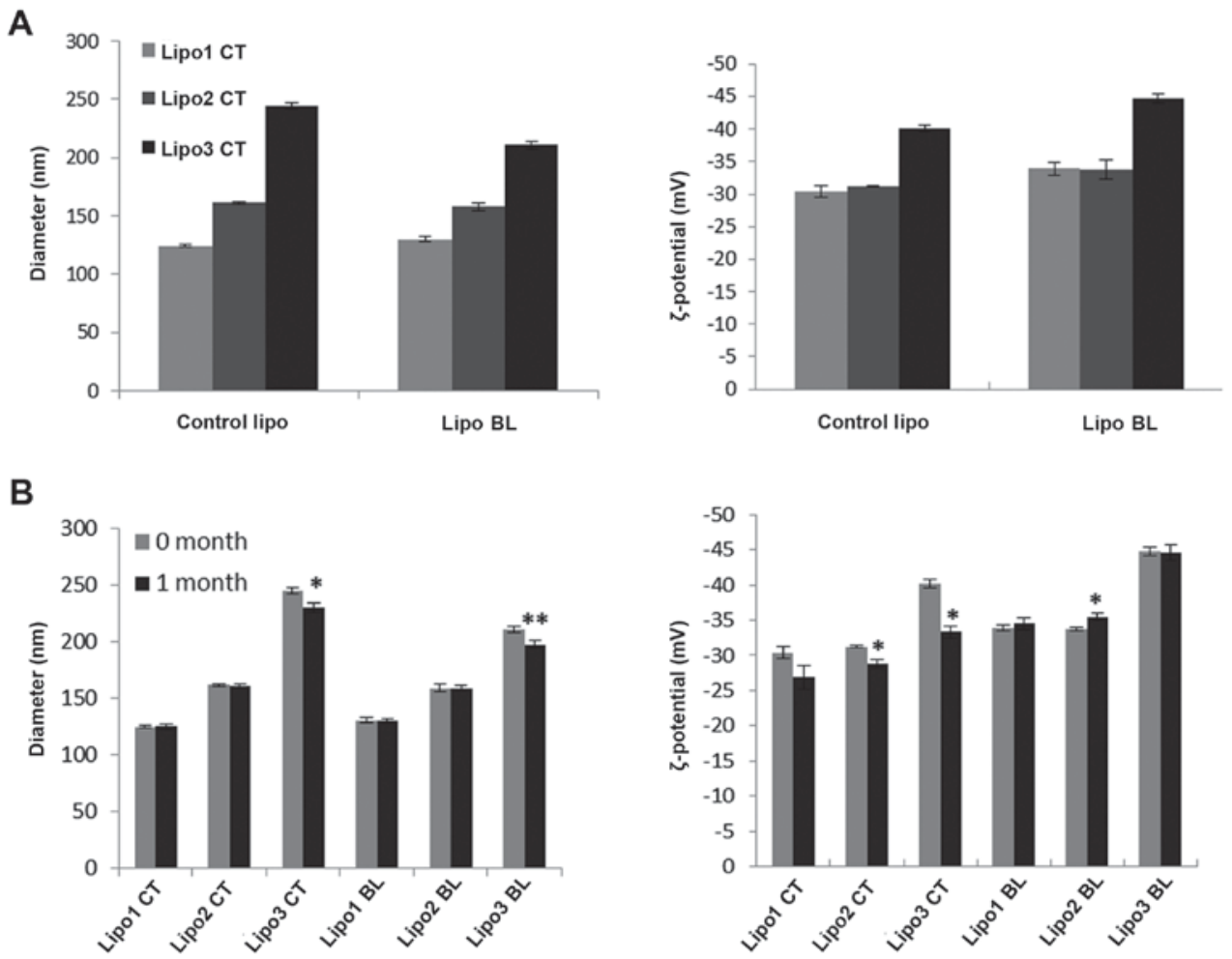

Figure 1. Determination of liposome sizes and stability over a 1 month period. (A) Characterization of the three groups of liposomes with different sizes (B) Diameter and $\zeta$-potential of the liposome formulations over a 1 month period. Data are shown as the mean \pm standard deviation of three replicate measurements in one representative experiment of at least two independent experiments. Using a paired t-test, significant changes in diameter were observed for lipo3 control and lipo3-BL following 1 month storage at $4^{\circ} \mathrm{C}$. Significant differences in $\zeta$-potential were observed for lipo2 control, lipo3 control and lipo2-BL following 1 month storage at $4^{\circ} \mathrm{C} .{ }^{*} \mathrm{P}<0.05$ and ${ }^{* *} \mathrm{P}<0.005$ vs. 0 months. Lipo1, $100 \mathrm{~nm}$ liposome; lipo2, $200 \mathrm{~nm}$ liposome; lipo3, $400 \mathrm{~nm}$ liposome; BL, baicalein; CT, control.

Statistical analysis. Results were presented as mean \pm standard deviation (SD). Statistical significance was tested by paired t-test or one-way ANOVA analysis. Differences between experimental groups were considered significant when the P-value $<0.05$.

\section{Results}

Liposome preparation and characterization. Three groups of liposome suspensions: lipol (100 nm), lipo2 (200 nm) and lipo3 $(400 \mathrm{~nm})$, were prepared to investigate whether the size of the liposomes contributed to the efficiency of BL encapsulation. BL/PC 1:10 (w/w) was dissolved in the solvent with lipid mixture when formulating the liposomes. Unincorporated $\mathrm{BL}$ was removed by dialysis and the concentration of $\mathrm{BL}$ in the liposome was determined by dissolving the liposomes in methanol. The absorbance of BL was recorded at $278 \mathrm{~nm}$ by FLUOstar Omega (BMG Labtech). Phospholipid (PC) was detected in the liposomes by the Stewart assay (36). Drug encapsulation efficiency was determined by encapsulated BL divided by original $\mathrm{BL}$ corrected by PC concentration. The final liposome samples were characterized and the data was shown in Table I, with the drug encapsulation efficiency from high to low: Lipo2 > lipo1 > lipo3.

The size and zeta potential of liposomes were determined by dynamic light scattering (Fig. 1A). Three groups of control liposomes displayed average diameters of 125, 161 and $230 \mathrm{~nm}$, respectively, with polydispersity of 0.1 for lipol
Table I. Characterisation of the liposomes.

\begin{tabular}{lccc}
\hline Sample & $\begin{array}{c}\text { Baicalein } \\
(\mathrm{mM})\end{array}$ & $\begin{array}{c}\text { PC } \\
(\mathrm{mg} / \mathrm{ml})\end{array}$ & $\begin{array}{c}\text { Drug } \\
\text { encapsulation (\%) }\end{array}$ \\
\hline $\begin{array}{l}\text { Control lipo1 } \\
(100 \mathrm{~nm})\end{array}$ & - & $18.6 \pm 1.2$ & - \\
Lipo1-BL & $2.3 \pm 0.1$ & $22.6 \pm 0.1$ & 28 \\
Control lipo2 & - & $20.3 \pm 0.9$ & - \\
$(200 \mathrm{~nm})$ & & & \\
Lipo2-BL & $2.5 \pm 0.2$ & $20.7 \pm 0.9$ & 32 \\
Control lipo3 & - & $18.0 \pm 1.3$ & - \\
$\begin{array}{l}\text { (400 nm) } \\
\text { Lipo3-BL }\end{array}$ & $2.0 \pm 0.3$ & $20.2 \pm 0.4$ & 26 \\
\hline
\end{tabular}

Data are presented as the mean \pm standard deviation of three replicate measurements. lipo1, $100 \mathrm{~nm}$ liposome; lipo2, $200 \mathrm{~nm}$ liposome; lipo3, 400 nm liposome; BL, baicalein; PC, phosphatidycholine.

and lipo2, 0.2 for lipo3. The average diameters for lipo2 and lipo3 were below 200 and $400 \mathrm{~nm}$, which may be due to the quality control of the filters (37). The negative $\zeta$-potential of the liposomes was attributed to one of the liposome components DSPE-PEG2000 which is negatively charged. The stability of liposomes was investigated by comparing the size and zeta potential changes over a one month storage period at $4^{\circ} \mathrm{C}$ in $10 \mathrm{mM}$ phosphate buffer $\mathrm{pH} 7.4$ (Fig. 1B). The results showed 


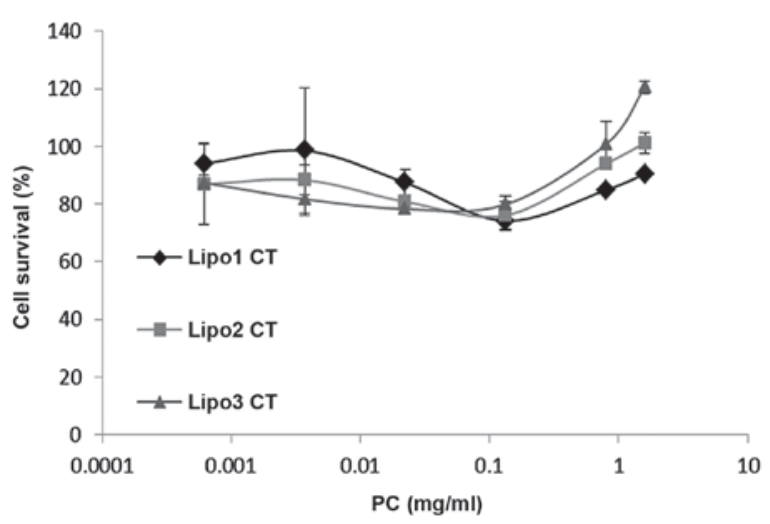

Figure 2. Cell viability of K562 cells following $48 \mathrm{~h}$ incubation with control liposomes. No significant difference in cell viability was observed against medium only treatment from one-way analysis of variance $(\mathrm{P}>0.05)$. Data are shown as the mean \pm standard deviation of three replicate measurements in one representative experiment of at least two independent experiments. Lipo1, $100 \mathrm{~nm}$ liposome; lipo2, $200 \mathrm{~nm}$ liposome; lipo3, $400 \mathrm{~nm}$ liposome; PC, phosphatidylcholine; CT, control.

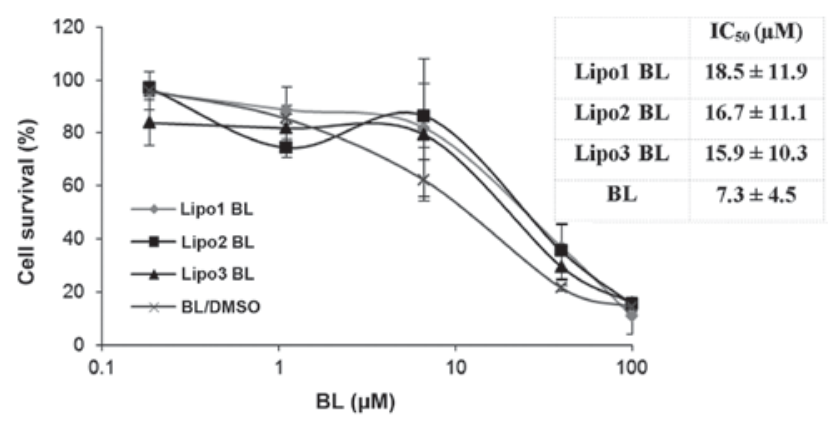

Figure 3. Effects of free BL and liposomal BL on cell proliferation as assessed by $\mathrm{CyQUANT}^{\circledR}$ assay. Liposomal BL demonstrated equivalent inhibitory effects on the growth of K562 cells when compared with free BL. No inhibitory effects were observed from the three groups of control liposomes from one-way analysis of variance $(\mathrm{P}>0.05)$. Values represent the mean \pm standard deviation of three replicate measurements in one representative experiment of three independent experiments. Lipo1, $100 \mathrm{~nm}$ liposome; lipo2, $200 \mathrm{~nm}$ liposome; lipo3, $400 \mathrm{~nm}$ liposome; BL, baicalein.

that lipo1 formulation was the most stable, with no statistically significant changes in diameter or $\zeta$-potential over at least a one month period.

In vitro cytotoxicity of the liposomes. Potential cytotoxicity of the liposomes was measured from cell viability relative to control K562 cells treated with medium only. MTS assay demonstrated that cell viability was between 80 and $120 \%$ in relation to the control samples (Fig. 2). Statistical analysis showed no evidence of liposome toxicity at phosphatidylcholine concentrations up to $1.6 \mathrm{mg} / \mathrm{ml}$.

Liposomal BL inhibits proliferation of K562 cells. The CyQUANT $^{\circledR}$ Direct Cell Proliferation Assay kit was used to evaluate the cytotoxicity of liposomal BL. The cell proliferation assay was assessed after cells were treated for $48 \mathrm{~h}$ with the encapsulated drug. Exposure to free and liposomal BL inhibited leukemia cell line K562 growth in a concentration-dependent manner (Fig. 3). The results showed that there was no significance difference between the antiproliferative

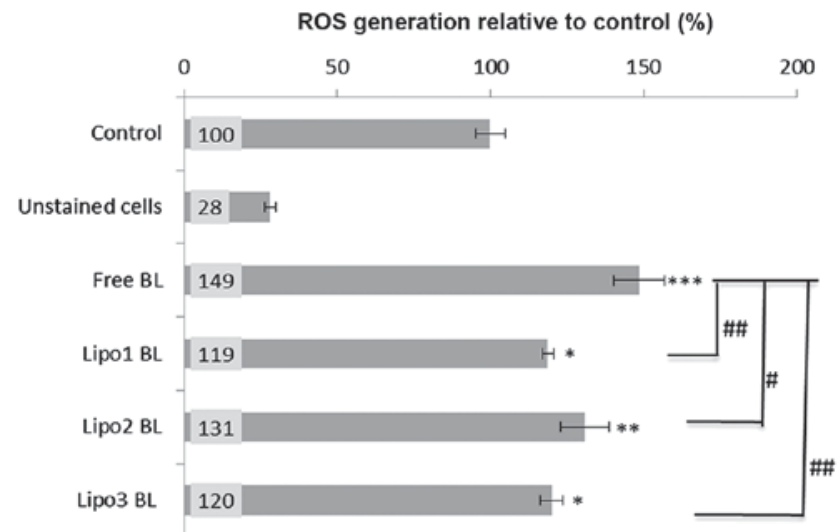

Figure 4. Effects of free BL and liposomal BL on intracellular ROS generation. K562 cells were stained with $20 \mu \mathrm{M}$ DCFDA following $24 \mathrm{~h}$ treatment with $20 \mu \mathrm{M} \mathrm{BL}$. The results are presented as the percentage increase of ROS relative to control (untreated cells only). Data are expressed as the mean \pm standard deviation of three replicate measurements in one representative experiment of two independent experiments. ${ }^{*} \mathrm{P}<0.05$, ${ }^{* *} \mathrm{P}<0.005$ and ${ }^{* * *} \mathrm{P}<0.001$ vs. control; ${ }^{\#} \mathrm{P}<0.05$ and ${ }^{\# \#} \mathrm{P}<0.005$, as indicated. Lipo1, $100 \mathrm{~nm}$ liposome; lipo2, $200 \mathrm{~nm}$ liposome; lipo3, $400 \mathrm{~nm}$ liposome; BL, baicalein; DCFDA, 2',7'-dichlorofluorescin diacetate; ROS, reactive oxygen species.

effects of liposomal BL and those of free BL at equimolar concentrations. No inhibition effects were observed from three groups of control liposomes, which was consistent with the MTS assay showing no cytotoxicity from the control liposomes.

Effect of BL on cell cycle progression and cell death. K562 cells were exposed to three different sizes of control liposomes and their relevant liposomal encapsulated BL for 48 h. Staining procedures using PI or Annexin V-FITC/PI were conducted to evaluate the effect of BL preparations on cell cycle and cell death, respectively, using a flow cytometer. Cells in each sample from different phases (sub-G1, $\mathrm{G} 1, \mathrm{~S}$ and $\mathrm{G} 2 / \mathrm{M}$ ) were presented and their percentage in each phase was calculated and shown in Table II; viable and non-viable (necrotic, early apoptotic and late apoptotic) cells were calculated and shown in Table III. All the BL preparations showed significant increase $(\mathrm{P}<0.005)$ in their populations in the sub-G1 phase and significant decrease $(\mathrm{P}<0.01)$ in cell viability in comparison of their relative control sample.

Intracellular ROS production. The cell permeant reagent DCFDA, a fluorogenic dye that measures ROS activity within cells, was used to investigate whether intracellular ROS production was involved in the mechanism of apoptosis caused by BL. Analysis indicated that all BL preparations induced significant ROS generation (as determined by the fluorescence changes normalized as percentage increase over the untreated cells control level). About 20-30\% increase $(\mathrm{P}<0.05)$ of ROS production was observed when K562 cells were treated with liposome encapsulated BL, and $50 \%$ increase $(\mathrm{P}<0.001)$ following treatment with non-encapsulated BL or free BL (Fig. 4). Moreover, there was a significant difference in ROS induction between the treatments with liposomal BL and free BL (Fig. 4). 
Table II. Percentage of cell populations in different stages of the cell cycle following exposure to $20 \mu \mathrm{M}$ BL or liposomal baicalein for $48 \mathrm{~h}$.

\begin{tabular}{lcccc}
\hline Treatment group & Sub-G1 phase & G1 phase & S phase & G2/M phase \\
\hline Untreated cells & $7.3 \pm 4.8$ & $45.4 \pm 2.6$ & $25.0 \pm 1.0$ & $22.8 \pm 7.5$ \\
Control lipo1 $(100 \mathrm{~nm})$ & $6.2 \pm 2.8$ & $43.1 \pm 0.8$ & $27.8 \pm 4.8$ & $23.1 \pm 6.4$ \\
Lipo1-BL & $17.9 \pm 4.9^{\mathrm{a}}$ & $41.7 \pm 1.5$ & $21.6 \pm 3.4$ & $19.4 \pm 2.7$ \\
Control lipo2 $(200 \mathrm{~nm})$ & $4.8 \pm 1.3$ & $46.3 \pm 3.0$ & $25.0 \pm 0.9$ & $23.4 \pm 5.6$ \\
Lipo2-BL & $19.9 \pm 3.3^{\mathrm{a}}$ & $38.6 \pm 1.8$ & $21.8 \pm 0.6$ & $20.1 \pm 5.5$ \\
Control lipo3 (400 nm) & $5.9 \pm 3.7$ & $43.8 \pm 0.7$ & $27.8 \pm 5.3$ & $22.7 \pm 7.6$ \\
Lipo3-BL & $16.3 \pm 2.4^{\mathrm{a}}$ & $39.9 \pm 2.1$ & $25.0 \pm 1.3$ & $20.0 \pm 0.7$ \\
DMSO & $4.7 \pm 2.4$ & $42.9 \pm 3.6$ & $23.4 \pm 0.1$ & $29.9 \pm 0.2$ \\
Free BL (in DMSO) & $23.3 \pm 11.5^{\mathrm{a}}$ & $36.5 \pm 8.1$ & $25.9 \pm 1.9$ & $15.3 \pm 5.4$
\end{tabular}

The results are presented as the average percentage of the cell population $(\%) \pm$ standard deviation. ${ }^{\mathrm{a}} \mathrm{P}<0.005 \mathrm{vs}$. untreated cells. lipo1, $100 \mathrm{~nm}$ liposome; lipo2, $200 \mathrm{~nm}$ liposome; lipo3, $400 \mathrm{~nm}$ liposome; BL, baicalein.

Table III. Percentage of cell populations of viable and non-viable cells exhibiting structural properties of different cell death types following exposure to $20 \mu \mathrm{M}$ BL or liposomal baicalein for $48 \mathrm{~h}$.

Non-viable cells

\begin{tabular}{lcccc}
\cline { 3 - 4 } Treatment group & Viable cells & Necrosis & Late apoptosis/secondary necrosis & Early apoptosis \\
\hline Untreated cells & $84.3 \pm 8.0$ & $1.4 \pm 0.5$ & $9.5 \pm 5.8$ & $4.9 \pm 1.6$ \\
Control lipo1 (100 nm) & $84.5 \pm 3.7$ & $1.1 \pm 0.1$ & $8.8 \pm 3.7$ & $5.6 \pm 0.1$ \\
Lipo1-BL & $65.8 \pm 3.9^{\mathrm{a}}$ & $4.6 \pm 1.0$ & $17.3 \pm 1.0$ & $12.3 \pm 3.8$ \\
Control lipo2 (200 nm) & $85.8 \pm 0.1$ & $3.7 \pm 3.8$ & $6.7 \pm 1.1$ & $3.9 \pm 2.9$ \\
Lipo2-BL & $65.1 \pm 2.2^{\mathrm{a}}$ & $4.0 \pm 0.9$ & $16.4 \pm 1.9$ & $14.5 \pm 5.0$ \\
Control lipo3 (400 nm) & $83.1 \pm 3.3$ & $1.2 \pm 0.6$ & $10.2 \pm 3.2$ & $5.6 \pm 0.6$ \\
Lipo3-BL & $64.9 \pm 0.9^{\mathrm{a}}$ & $4.4 \pm 0.7$ & $16.3 \pm 2.7$ & $14.5 \pm 4.3$ \\
DMSO & $85.2 \pm 2.7$ & $3.1 \pm 3.3$ & $7.4 \pm 2.1$ & $4.2 \pm 3.8$ \\
Free BL (in DMSO) & $64.3 \pm 5.3^{\mathrm{a}}$ & $2.9 \pm 0.5$ & $15.5 \pm 4.1$ & $17.3 \pm 1.7$ \\
\hline
\end{tabular}

The results are presented as the average percentage of the cell population $(\%) \pm$ standard deviation. ${ }^{\mathrm{a}} \mathrm{P}<0.01 \mathrm{vs}$. untreated cells. lipo1, $100 \mathrm{~nm}$ liposome; lipo2, $200 \mathrm{~nm}$ liposome; lipo3, $400 \mathrm{~nm}$ liposome; BL, baicalein.

\section{Discussion}

BL is a potent antitumor agent, but its poor solubility in aqueous solution, instability and relative toxicity affect its bioavailability and application in humans. In this study, we prepared three groups of liposomal BL with different sizes to enhance its solubility and stability and investigated their ability to affect proliferation of CML K562 cells in vitro. Earlier research has shown that uncoated liposomes were quickly cleared from the blood by the reticuloendothelial system (38). Therefore, liposomes coated with polyethylene glycol (PEG), shown to increase oral bioavailability of BL in vivo (11), were employed in this study.

A previous study has demonstrated that internalization of liposomes by murine macrophages was similar with liposome size of between 100 and $200 \mathrm{~nm}$, but was 1.7 times higher with liposomes larger than $400 \mathrm{~nm}$, indicating that the degree of internalization is positively related to the size of the liposome (39). These researchers also suggested that PEG coating significantly reduced endocytosis of liposomes (39). However, others have reported that immunoliposomes of $\sim 100 \mathrm{~nm}$ in size may be ideal for intraperitoneal and intravenous (i.p./i.v.) administration in order to achieve high plasma concentration and subsequent tumor targeting using tumor vasculature, whereas immunoliposomes of a larger size ( $>300-400 \mathrm{~nm}$ ) may be preferable for i.p. administration and retention of the liposomes in the peritoneal cavity for targeting tumors located in this site and surrounding areas (40).

In this study, three groups of liposome formulations with diameters of 100, 200 or $400 \mathrm{~nm}$ were evaluated for their stability, drug encapsulation efficiency, cytotoxicity, and pro-apoptotic effects on K562 cells. The results showed that the $100 \mathrm{~nm}$ liposome formulation was the most stable, with no significant changes in diameter or zeta potential over at least a one month period. The $200 \mathrm{~nm}$ liposome showed the highest drug encapsulation efficiency. Liposomal BL displayed similar 
cell-killing capabilities against the K562 cell line compared to free BL, indicating that liposomes could be a potential platform for BL delivery to K562 leukemia cells due to increased solubility and stability.

Previous investigations have shown that BL exerts an antitumor effect by promoting apoptosis or inhibiting the proliferation of cancer cells (29-32) through multiple signalling pathways $(33,34)$. For example, BL induces human osteosarcoma cell line MG-63 via ROS-induced BNIPs expression (41) and it also induces G1 arrest in oral cancer cells by enhancing the degradation of cyclin D1 and activating AhR to decrease $\mathrm{Rb}$ phosphorylation. We suspected that the anti-proliferative effect on K562 of BL is associated with ROS generation and cell cycle arrest. Therefore, in this study we investigated the molecular mechanisms by evaluating the generation of ROS and through cell cycle analysis. Significantly increased ROS production was observed when K562 cells were treated with both encapsulated and non-encapsulated BL compared to untreated control cells (Fig. 4). However, the results revealed that there was no obvious cell cycle arrest observed after treatment with free or liposomal BL (but showed an accumulation of apoptotic cell in the sub-G1 phase) suggesting that BL induced K562 cell apoptosis is, in part, via ROS generation. Interestingly, more intracellular ROS was produced from cells treated with free BL compared with those treated with liposomal BL, although no significant difference in cell apoptosis was observed. This suggests that other mechanisms may also be involved in BL induced K562 cell death.

ROS production occurs during normal metabolic functions such as respiration (42) and the detoxification of xenobiotics. ROS can cause cell death or lead to mutagenesis and increased cell proliferation depending of its relative amount compared to levels of endogenous antioxidants in the cells. Elevated ROS levels in cells can cause genetic mutations which can trigger programmed cell death via the mitochondrial (intrinsic) pathway of apoptosis (43), but may also result in normal cells becoming cancerous (42). Cancer cells increase their rate of ROS production compared with normal cells to hyperactivate the cell signalling pathways necessary for cellular transformation and tumorigenesis. Meanwhile, they increase the antioxidant capacity to maintain ROS homeostasis and evade cell death $(42,44,45)$. This altered redox environment of cancer cells may make them more susceptible to ROS-manipulated therapies. It has been proposed that a disproportional increase in intracellular ROS can induce cancer cell cycle arrest, senescence and apoptosis. Apoptosis is linked to an increase in mitochondrial oxidative stress that causes cytochrome $c$ release, an irrevocable event that leads to the activation of caspases and cell death $(46,47)$. BL has been shown to trigger this apoptotic death program through ROS-mediated mitochondrial dysfunction pathway in HL-60 cells (48). This was further confirmed by the other studies on human bladder cancer cells and osteosarcoma cell line $(41,49)$. Our results indicated the same finding that BL induced cancer cell death by generation of ROS or/and possibly by depletion of cells from antioxidant proteins which protect cells from ROS-mediated apoptosis. The difference in the ROS generation by free BL and liposomal BL suggests that other signalling pathways could be involved in the liposome-BL induced cell death. Further studies in the future are required to identify other possible mechanisms of action of liposome-delivered BL induction of myeloid leukemia cell death.

In this study, three groups of liposome formulations with diameters of 100, 200 and $400 \mathrm{~nm}$ were synthesized. The results demonstrated that the $100 \mathrm{~nm}$ liposome was the most stable formulation and that liposomal BL had an equivalent cytotoxic effect on K562 cells compared with free $\mathrm{BL}$, indicating that liposomes may be a potential route for the delivery of BL with better solubility and stability. Enhanced intracellular ROS generation was induced by all BL preparations, but no significant cell cycle arrest was seen in any of the phases following liposomal BL or free BL treatment, indicating that the mechanism involved in K562 cell apoptosis following BL treatment was at least in part via ROS generation. The findings are important as BL has been shown to be potent in killing several cancer cell lines. However, the hydrophobic nature of the drug hinders its application in vivo. The results from this study are promising in demonstrating the ability of liposome-encapsulated BL to exert cytotoxicity on human chronic myeloid leukemic cells. However, further studies are required to determine if the liposomal formulation exerts selective cytotoxicity in leukemic cells compared to normal cells and to evaluate further possible mechanisms of action of the drug.

\section{References}

1. Wang Y, Wei S, Wang J, Fang Q and Chai Q: Phenethyl isothiocyanate inhibits growth of human chronic myeloid leukemia K562 cells via reactive oxygen species generation and caspases. Mol Med Rep 10: 543-549, 2014.

2. Melo JV and Barnes DJ: Chronic myeloid leukaemia as a model of disease evolution in human cancer. Nat Rev Cancer 7: 441-453, 2007.

3. Owen HC, Appiah S, Hasan N, Ghali L, Elayat G and Bell C: Phytochemical modulation of apoptosis and autophagy: Strategies to overcome chemoresistance in leukemic stem cells in the bone marrow microenvironment. Int Rev Neurobiol 135: 249-278, 2017.

4. Yan H, Xin S, Wang H, Ma J, Zhang $\mathrm{H}$ and Wei $\mathrm{H}$ : Baicalein inhibits MMP-2 expression in human ovarian cancer cells by suppressing the $\mathrm{p} 38$ MAPK-dependent NF- $\mathrm{KB}$ signaling pathway. Anticancer Drugs 26: 649-656, 2015.

5. Guo Z, Hu X, Xing Z, Xing R, Lv R, Cheng X, Su J, Zhou Z, $\mathrm{Xu} Z$, Nilsson S and Liu Z: Baicalein inhibits prostate cancer cell growth and metastasis via the caveolin-1/AKT/mTOR pathway. Mol Cell Biochem 406: 111-119, 2015.

6. Wang N, Ren D, Deng S and Yang X: Differential effects of baicalein and its sulfated derivatives in inhibiting proliferation of human breast cancer MCF-7 cells. Chem Biol Interact 221: 99-108, 2014

7. Peng Y, Guo C, Yang Y, Li F, Zhang Y, Jiang B and Li Q: Baicalein induces apoptosis of human cervical cancer HeLa cells in vitro. Mol Med Rep 11: 2129-2134, 2015.

8. Lee HZ, Leung HW, Lai MY and Wu CH: Baicalein induced cell cycle arrest and apoptosis in human lung squamous carcinoma CH27 cells. Anticancer Res 25: 959-964, 2005.

9. He X, Pei L, Tong HH and Zheng Y: Comparison of spray freeze drying and the solvent evaporation method for preparing solid dispersions of baicalein with Pluronic F68 to improve dissolution and oral bioavailability. AAPS PharmSciTech 12: 104-113, 2011.

10. Lai MY, Hsiu SL, Tsai SY, Hou YC and Chao PD: Comparison of metabolic pharmacokinetics of baicalin and baicalein in rats. J Pharm Pharmacol 55: 205-209, 2003.

11. Liang J, Wu W, Liu Q and Chen S: Long-circulating nanoliposomes (LCNs) sustained delivery of baicalein (BAI) with desired oral bioavailability in vivo. Drug Deliv 20: 319-323, 2013.

12. de Oliveira MR, Nabavi SF, Habtemariam S, Erdogan Orhan I, Daglia M and Nabavi SM: The effects of baicalein and baicalin on mitochondrial function and dynamics: A review. Pharmacol Res 100: 296-308, 2015. 
13. Zhang L, Lin G, Chang Q and Zuo Z: Role of intestinal first-pass metabolism of baicalein in its absorption process. Pharm Res 22: 1050-1058, 2005.

14. Fong YK, Li CR, Wo SK, Wang S, Zhou L, Zhang L, Lin G and Zuo Z: In vitro and in situ evaluation of herb-drug interactions during intestinal metabolism and absorption of baicalein. J Ethnopharmacol 141: 742-753, 2012.

15. Seo MJ, Choi HS, Jeon HJ, Woo MS and Lee BY: Baicalein inhibits lipid accumulation by regulating early adipogenesis and m-TOR signaling. Food Chem Toxicol 67: 57-64, 2014.

16. Tsai TH, Liu SC, Tsai PL, Ho LK, Shum AY and Chen CF: The effects of the cyclosporin A, a P-glycoprotein inhibitor, on the pharmacokinetics of baicalein in the rat: A microdialysis study. Br J Pharmacol 137: 1314-1320, 2002.

17. Tian S, He G, Song J, Wang S, Xin W, Zhang D and Du G Pharmacokinetic study of baicalein after oral administration in monkeys. Fitoterapia 83: 532-540, 2012.

18. Tan ML, Choong PF and Dass CR: Recent developments in liposomes, microparticles and nanoparticles for protein and peptide drug delivery. Peptides 31: 184-193, 2010.

19. Huang YB, Tsai MJ, Wu PC, Tsai YH, Wu YH and Fang JY: Elastic liposomes as carriers for oral delivery and the brain distribution of (+)-catechin. J Drug Target 19: 709-718, 2011.

20. Park SJ, Choi SG, Davaa E and Park JS: Encapsulation enhancement and stabilization of insulin in cationic liposomes. Int J Pharm 415: 267-272, 2011.

21. Song YK, Hyun SY, Kim HT, Kim CK and Oh JM: Transdermal delivery of low molecular weight heparin loaded in flexible liposomes with bioavailability enhancement: Comparison with ethosomes. J Microencapsul 28: 151-208, 2011.

22. Cansell M, Nacka F and Combe N: Marine lipid-based liposomes increase in vivo FA bioavailability. Lipids 38: 551-559, 2003.

23. Guan P, Lu Y, Qi J, Niu M, Lian R, Hu F and Wu W: Enhanced oral bioavailability of cyclosporine A by liposomes containing a bile salt. Int J Nanomedicine 6: 965-974, 2011.

24. Isacchi B, Arrigucci S, la Marca G, Bergonzi MC, Vannucchi MG, Novelli A and Bilia AR: Conventional and long-circulating liposomes of artemisinin: Preparation, characterization, and pharmacokinetic profile in mice. J Liposome Res 21: 237-244, 2011.

25. Vural I, Sarisozen C and Olmez SS: Chitosan coated furosemide liposomes for improved bioavailability. J Biomed Nanotechnol 7: 426-430, 2011

26. Kim HP, Son KH, Chang HW and Kang SS: Anti-inflammatory plant flavonoids and cellular action mechanisms. J Pharmacol Sci 96: 229-245, 2004.

27. Lu Y, Joerger R and Wu C: Study of the chemical composition and antimicrobial activities of ethanolic extracts from roots of Scutellaria baicalensis Georgi. J Agric Food Chem 59: 10934-10942, 2011.

28. Shieh DE, Liu LT and Lin CC: Antioxidant and free radical scavenging effects of baicalein, baicalin and wogonin. Anticancer Res 20: 2861-2865, 2000

29. Chao JI, Su WC and Liu HF: Baicalein induces cancer cell death and proliferation retardation by the inhibition of CDC2 kinase and survivin associated with opposite role of p38 mitogen-activated protein kinase and AKT. Mol Cancer Ther 6: 3039-3048, 2007.

30. Chen H, Gao Y, Wu J, Chen Y, Chen B, Hu J and Zhou J: Exploring therapeutic potentials of baicalin and its aglycone baicalein for hematological malignancies. Cancer Lett 354: 5-11, 2014.

31. Cheng YH, Li LA, Lin P, Cheng LC, Hung CH, Chang NW and Lin C: Baicalein induces G1 arrest in oral cancer cells by enhancing the degradation of cyclin D1 and activating AhR to decrease $\mathrm{Rb}$ phosphorylation. Toxicol Appl Pharmacol 263. 360-367, 2012 .

32. Ma GZ, Liu CH, Wei B, Qiao J, Lu T, Wei HC, Chen HD and He CD: Baicalein inhibits DMBA/TPA-induced skin tumorigenesis in mice by modulating proliferation, apoptosis, and inflammation. Inflammation 36: 457-467, 2013.
33. Chow JM, Shen SC, Wu CY and Chen YC: 12-o-Tetradecanoylphorbol 13-acetate prevents baicalein-induced apoptosis via activation of protein kinase $\mathrm{C}$ and JNKs in human leukemia cells. Apoptosis 11: 1999-2011, 2006.

34. Lee JH, Li YC, Ip SW, Hsu SC, Chang NW, Tang NY, Yu CS, Chou ST, Lin SS, Lino CC, et al: The role of $\mathrm{Ca}^{2+}$ in baicalein-induced apoptosis in human breast MDA-MB-231 cancer cells through mitochondria- and caspase-3-dependent pathway. Anticancer Res 28: 1701-1711.

35. Wang X, Li D, Ghali L, Xia R, Munoz LP, Garelick H, Bell C and Wen X: Therapeutic potential of delivering arsenic trioxide into HPV infected cervical cancer cells using liposomal nanotechnology. Nanoscale Res Lett 11: 94, 2016

36. Wang SX, Michiels J, Ariën KK, New R, Vanham G and Roitt I: Inhibition of HIV virus by neutralizing Vhh attached to dual functional liposomes encapsulating dapivirine. Nanoscale Res Lett 11: 350, 2016.

37. Berger N, Sachse A, Bender J, Schubert R and Brandl M: Filter extrusion of liposomes using different devices: Comparison of liposome size, encapsulation efficiency and process characteristics. Int J Pharm 223: 55-68, 2001.

38. Clayton R, Ohagen A, Nicol F, Del Vecchio AM, Jonckers TH, Goethals O, Van Loock M, Michiels L, Grigsby J, Xu Z, et al: Sustained and specific in vitro inhibition of HIV-1 replication by a protease inhibitor encapsulated in gp120-targeted liposomes. Antiviral Res 84: 142-149, 2009.

39. Lee JS, Hwang SY and Lee EK: Imaging-based analysis of liposome internalization to macrophage cells: Effects of liposome size and surface modification with PEG moiety. Colloids Surf B Biointerfaces 136: 786-790, 2015.

40. Feng J, Iyer A, Seo Y, Broaddus C, Liu B, VanBrocklin H and $\mathrm{He} \mathrm{J}$ : Effects of size and targeting ligand on biodistribution of liposome nanoparticles in tumor mice. Soc Nucl Med Annu Meet Abstr 54: 1339, 2013.

41. Ye F, Wang H, Zhang L, Zou Y, Han H and Huang J: Baicalein induces human osteosarcoma cell line MG-63 apoptosis via ROS-induced BNIP3 expression. Tumor Biol 36: 4731-4740, 2015.

42. Reczek CR and Chandel NS: The two faces of reactive oxygen species in cancer. Annu Rev Cancer Biol 1: 79-98, 2017.

43. Galadari S, Rahman A, Pallichankandy S and Thayyullathil F: Reactive oxygen species and cancer paradox: To promote or to suppress? Free Radic Biol Med 104: 144-164, 2017.

44. Liou GY and Storz P: Reactive oxygen species in cancer. Free Radic Res 44: 479-496, 2010

45. Nieborowska-Skorska M, Kopinski PK, Ray R, Hoser G, Ngaba D, Flis S, Cramer K, Reddy MM, Koptyra M, Penserga T, et al: Rac2-MRC-cIII-generated ROS cause genomic instability in chronic myeloid leukemia stem cells and primitive progenitors. Blood 119: 4253-4263, 2012.

46. Simon HU, Haj-Yehia A and Levi-Schaffer F: Role of reactive oxygen species (ROS) in apoptosis induction. Apoptosis 5: 415-418, 2000

47. Cadenas E: Mitochondrial free radical production and cell signaling. Mol Aspects Med 25: 17-26, 2004

48. Wang J, Yu Y, Hashimoto F, Sakata Y, Fujii M and Hou DX: Baicalein induces apoptosis through ROS-mediated mitochondrial dysfunction pathway in HL-60 cells. Int J Mol Med 14: 627-632, 2004

49. Choi EO, Park C, Hwang HJ, Hong SH, Kim GY, Cho EJ, Kim WJ and Choi YH: Baicalein induces apoptosis via ROS-dependent activation of caspases in human bladder cancer 5637 cells. Int J Oncol 49: 1009-1018, 2016

This work is licensed under a Creative Commons Attribution-NonCommercial-NoDerivatives 4.0 International (CC BY-NC-ND 4.0) License. 